Bull. Mater. Sci., Vol. 6, No. 6, December 1984, pp. 1029-1033. (C) Printed in India.

\title{
Annealing behaviour of electron-beam deposited tin dioxide films
}

\author{
ARJEESH GUPTA, POONAM GUPTA and V K SRIVASTAVA \\ Department of Physics, University of Roorkee, Roorkee 247672 , India \\ MS received 23 November 1983; revised 31 March 1984
}

\begin{abstract}
The sheet resistivity of tin dioxide films deposited by electron-beam evaporation has been studied during annealing, both as a function of time and temperature. The annealing behaviour of $\mathrm{SnO}_{2}$ films under the above two different conditions is consistent. A qualitative interpretation has been given for the decrease and the minimum observed in the resistivity. The increase in resistivity has been confirmed by scanning-electron micrographs. The films were also characterized by $\mathrm{x}$-ray diffractometry.
\end{abstract}

Keywords. Tin dioxide films; electron beam evaporation; annealing behaviour; sheet resistivity.

\section{Introduction}

Thin transparent conducting films of $\mathrm{SnO}_{2}$, because of their wide application in solar cells, have currently become a subject of intense investigation. The $\mathrm{SnO}_{2}$ film is a transparent conductor which is sometimes known as Nesa glass (Ishiguro et al 1958). The optical and electrical properties of $\mathrm{SnO}_{2}$ films were studied by Arai (1960) who found them to be polycrystalline $n$-type degenerate semiconductor with a free carrier density of $7 \times 10^{18}-1.7 \times 10^{19} \mathrm{~cm}^{-3}$ and an energy band gap of about $3.5 \mathrm{eV}$. The change in the conductivity of the material $\left(\mathrm{SnO}_{2}\right)$ in thin films as compared to that in bulk arises due to anion oxygen defects.

It is known (Raccanelli and Madalena 1976; Viscrian and Georgescu 1969; Shanthi et al 1980) that post-annealing treatment of $\mathrm{SnO}_{2}$ films can result in change of electrical properties. It has recently been reported (Ghosh et al 1978; Nagatoma et al 1979) that the annealing of $\mathrm{SnO}_{2}$ films plays an important role in the improvement of the performance characteristics of $\mathrm{SnO}_{2} / \mathrm{Si}$ solar cells. It has been found that on annealing the resistivity of pure $\mathrm{SnO}_{2}$ single crystals reduces and that of the $\mathrm{SnO}_{2}$ films deposited by hydrolysis of an ether-alcohol solution of $\mathrm{Sn}\left(\mathrm{OC}_{2} \mathrm{H}_{5}\right)_{4}$ first decreases and then increases drastically on annealing at temperatures higher than $500^{\circ} \mathrm{K}$ (Jarzebeski 1976). But no satisfactory explanation is available for the phenomenon.

As far as the authors are aware, investigations on the annealing behaviour of electron beam deposited $\mathrm{SnO}_{2}$ film, which are important in solar cells, have not been reported. The present work was therefore undertaken.

\section{Experimental}

\subsection{Sample preparation}

$\mathrm{SnO}_{2}$ films were prepared by electron-beam evaporation at a pressure $\sim 10^{-6}$ torr. Undoped $\mathrm{SnO}_{2}(99.90 \%)$ was evaporated by an electron-beam gun onto chemically 
cleaned glass substrates at room temperature $\left(300^{\circ} \mathrm{K}\right)$. An evaporation rate of $4 \AA \mathrm{sec}^{-1}$ was maintained to produce films of $\mathrm{SnO}_{2}$ with approximately uniform thickness of about $1300 \AA$. The thickness of the films was measured during evaporation by a quartz crystal thickness monitor and also by the interferometry method.

\subsection{Resistivity measurement}

The resistivity of the films was measured in a furnace during annealing as a function of time. The temperature of the furnace was maintained constant $\left( \pm 5^{\circ} \mathrm{C}\right)$. The sheet resistivity of $\mathrm{SnO}_{2}$ films was also measured during annealing as a function of temperature in the range $(623-808 \mathrm{~K})$. The temperature of the furnace was regulated at approximately $3^{\circ} \mathrm{C} / \mathrm{min}$. The temperature was measured with a chromel-alumel thermocouple. X-ray diffraction measurements of the films were made (Philips X-ray diffractometer, model No. PW-1140/90) and scanning electron micrographs taken (SEM-501, Philips make).

\section{Results and discussion}

The sheet resistivity of the as-deposited $\mathrm{SnO}_{2}$ films was very high (>20 M $\Omega$ ) and decreased with annealing in air. The variation of sheet resistivity as a function of time during isothermal annealing at different temperatures is shown in figure 1 . The asdeposited or unannealed $\mathrm{SnO}_{2}$ films (evaporation temperature above $1800^{\circ} \mathrm{C}$ ) are expected to be amorphous in character as shown by its high resistivity. This amorphous character is confirmed by $x$-ray diffractometric characterisation (figure $2 a$ ). The peaks of the $x$-ray diffraction pattern show crystallization with time during annealing at 717 , 701 and $688 \mathrm{~K}$ respectively (figure 2 ) as also indicated by decrease in resistivity. As expected, the general shape of the isothermal annealing curves (figure 1), at different temperatures is very similar.

It was observed that the time at which the films became conducting increases as the annealing temperature decreases. This is expected because the thermally activated process of transformation from the amorphous to the polycrystalline phase will slow down with decrease of annealing temperature. This also explains the broadening of the minima with decreasing annealing temperature. The decrease in sheet resistivity with time (figure 1) may be attributed to the reduction in defect density as shown by the $x$-ray diffraction results, and in addition chemisorption of oxygen also takes place which further reduces the resistivity of the films (Shanthi et al 1980). The sheet resistivity attains a minimum when the defect distribution may be assumed to be in equilibrium (Chopra 1969). The increase in the observed resistivity after the minimum is dominated by the formation of pores and further increase in size of the pores. The SEM photographs (figures $3 \mathrm{a}, \mathrm{b}$ ) corresponding to 37 and $60 \mathrm{~min}$ annealing give only pores with their size increasing.

The variation in sheet resistivity with temperature on annealing the $\mathrm{SnO}_{2}$ film in air is plotted in figure 4 . The film showed irreversible decrease in sheet resistivity, perhaps due to the reduction of defect density with increasing temperature. This mechanism governing the resistivity of films is well known (Maissel and Glang 1970). The minimum nearly corresponds to the Debye temperature of $\mathrm{SnO}_{2}\left[\sim 500^{\circ} \mathrm{K}\right]$, so that the largest 
Tin dioxide films

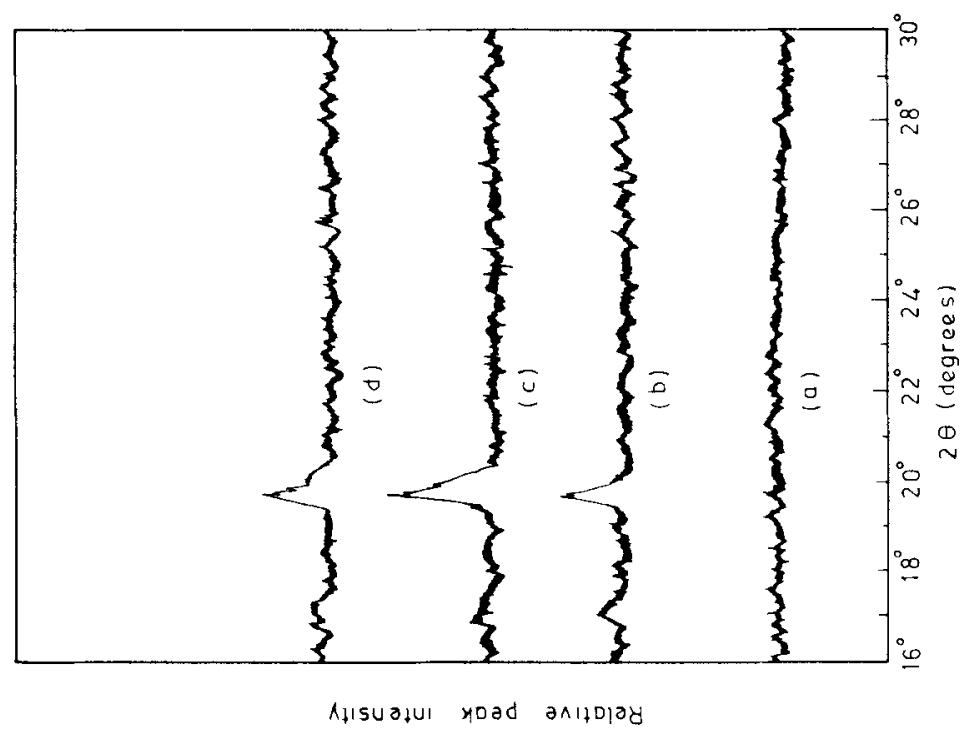

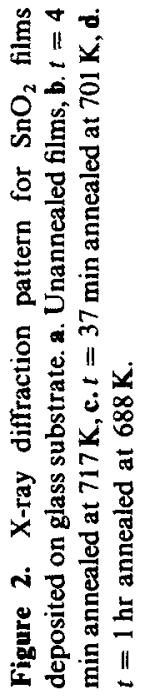
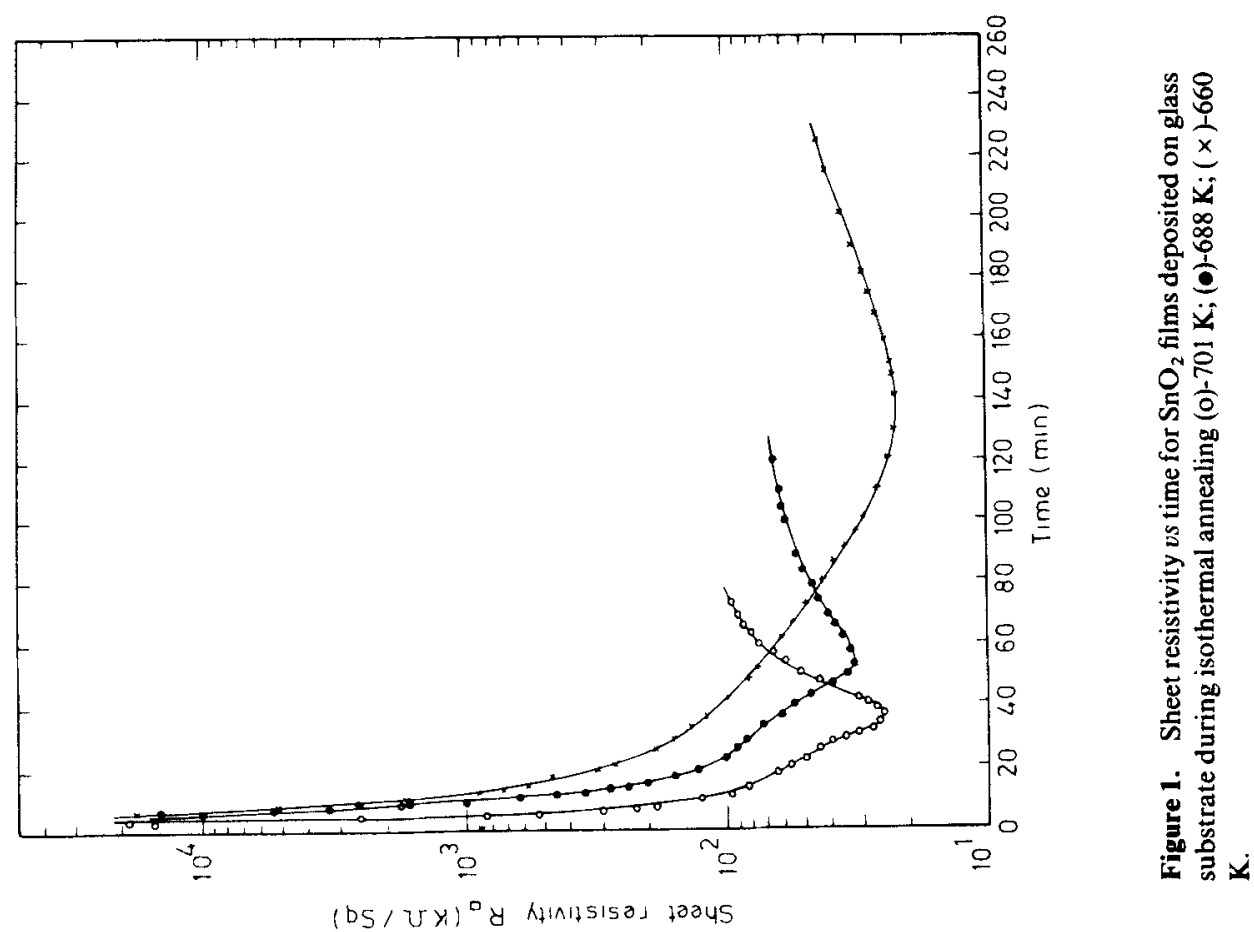

(bS/UX) ${ }^{\circ}$ y kinis 150 da245 


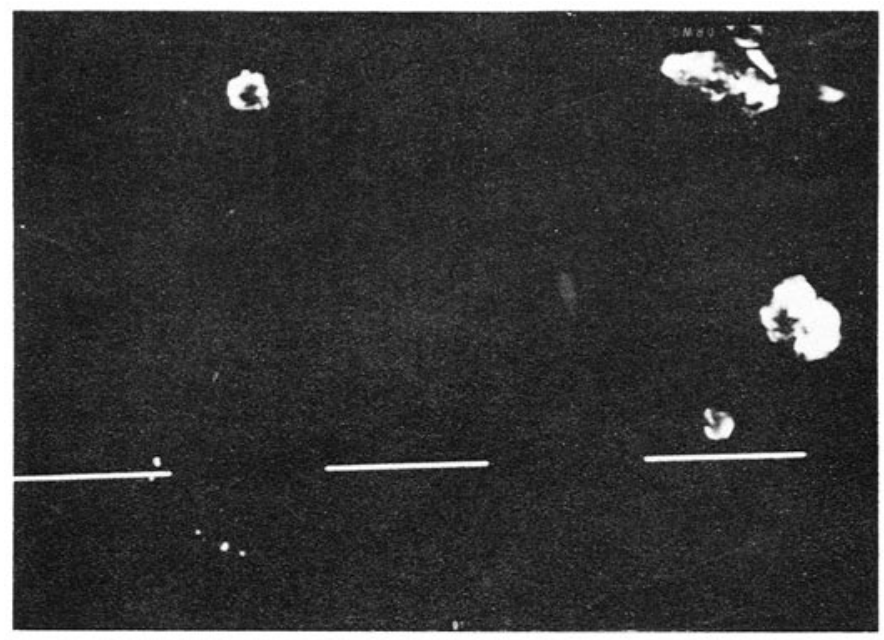

(a)

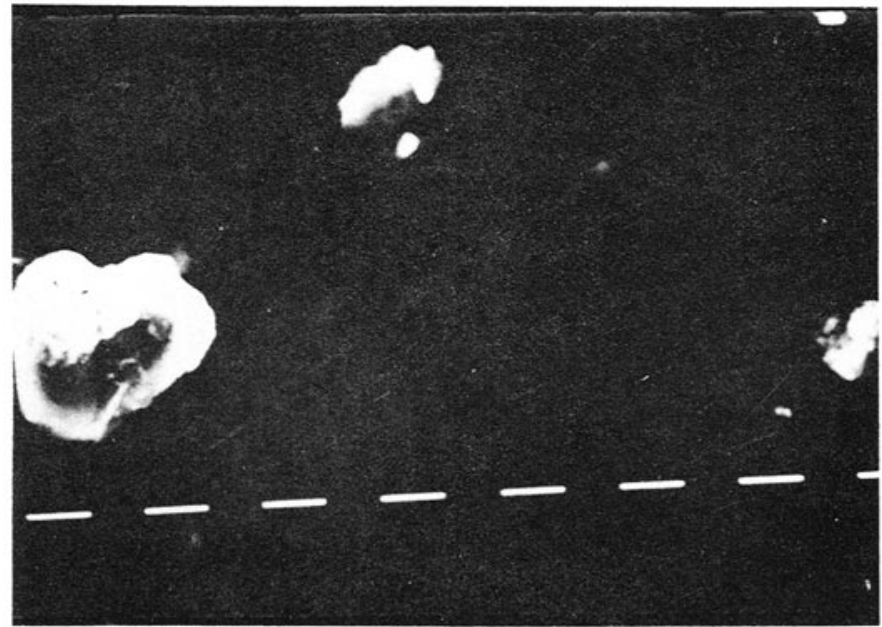

(b)

Figure 3. Scanning electron micrograph of $\mathrm{SnO}_{2}$ films deposited on a glass substrate annealed at $701 \mathrm{~K}$, a. annealed for $37 \mathrm{~min}$ (magnification: $160 \times 1 \cdot 1$ ). b. annealed for $1 \mathrm{hr}$ (magnification $640 \times 1$ ).

part of the lattice defects is removed because of the maximum frequency of the lattice vibrations (Chopra 1969). Therefore, beyond this point the resistivity increases.

We have attempted here to give a qualitative interpretation of the results obtained on the annealing behaviour of tin dioxide films. A quantitative study is in progress.

\section{Acknowledgement}

AG and PG are thankful to CSIR (India) for financial support. The authors express their sincere thanks to Mr N K Saini for help in carrying out SEM experiments. 


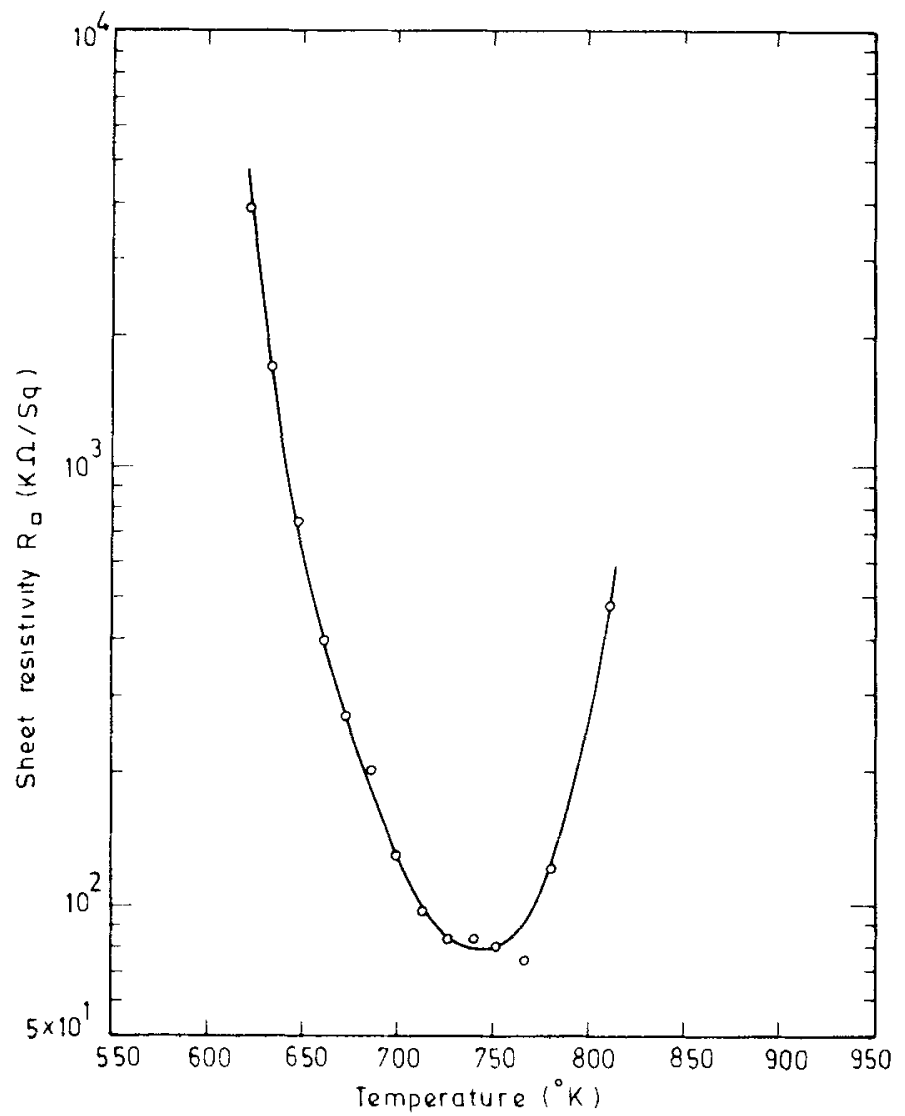

Figure 4. Sheet resistivity us temperature for $\mathrm{SnO}_{2}$ film deposited on a glass substrate.

\section{References}

Arai T 1960 J. Phys. Soc. Jpn 15916

Chopra K L 1969 Thin film phenomenon (New York: McGraw Hill) 381-387

Ghosh A K, Fishman C and Feng T 1978 J. Appl. Phys. 493490

Ishiguro K, Sasaki T, Arai T and Imai I 1958 J. Phys. Soc. Jpn 13296

Jarzebeski Z M 1976 J. Electrochemical Soc. 123 299C

Maissel L I and Glang R 1970 Handbook of thin films technology (New York: McGraw Hill) 13-26

Nagatoma T; Endo M and Omoto O 1979 Jpn J. Appl. Phys. 181103

Raccanelli A and Madalena A 1976 J. Am. Ceram. Soc. 59425

Shanthi E, Banerjee A, Dutta V and Chopra K L 1980 Thin Solid Films 71237

Viscrian I and Georgescu V 1969 Thin Solid Films 3 R17 